\title{
Efeitos de uma Intervenção na Abordagem Fônica em Alunos com Dificuldades de Alfabetização
}

\author{
Maria Inês de Souza Vitorino Justino ${ }^{1}$ \\ Sylvia Domingos Barrera \\ Universidade de São Paulo (Ribeirão Preto)
}

\begin{abstract}
RESUMO - Este estudo buscou avaliar os efeitos de uma intervenção baseada na utilização de abordagem fônica associada ao desenvolvimento da consciência fonológica, em alunos com graves defasagens na alfabetização. Participaram da pesquisa 31 alunos de $4^{\mathrm{a}}$ a $8^{\mathrm{a}}$ séries de uma escola pública, com idade média de 11,9 anos. A pesquisa seguiu o delineamento pré-teste/ intervenção/ pós-teste. No pré-teste foram avaliadas as habilidades de consciência fonológica, conhecimento de letras, leitura e escrita. A intervenção ocorreu em duas aulas semanais, de duas horas cada, durante 10 meses. No pós-teste, foram reavaliadas as mesmas habilidades do pré-teste. Análises estatísticas mostraram diferenças significativas entre pré e pós-teste para todas as habilidades avaliadas, sugerindo a eficácia da intervenção realizada para a alfabetização dos participantes.
\end{abstract}

Palavras-chave: alfabetização; consciência fonológica; fracasso escolar; método fônico.

\section{Effects of a Phonics Intervention in Students with Difficulties in Literacy}

\begin{abstract}
This study evaluated the effects of an intervention based on phonics approach associated with phonological awareness given to students with serious gaps in literacy. The 31 participants had a mean age of 11.9 years and were attending 4 th to 8 th grades of elementary school. The research comprised three phases: pre-test, intervention and post-test. In the pretest letter knowledge, phonological awareness, reading and writing abilities were assessed. The intervention occurred during two hours per week, for a 10 month period. In the post-test, a reassessment of the same abilities of the pre-test was performed. Statistical analysis showed significant differences between pre and post-test for all abilities evaluated, suggesting the efficacy of the intervention in increasing the literacy abilities of the participants.
\end{abstract}

Keywords: literacy; phonological awareness; school failure; phonics.

A escola pública é resultado da luta popular pela democratização do conhecimento. Porém, se atualmente no Brasil ela já é universal, atendendo a praticamente 100\% das crianças que dela dependem, o mesmo não se pode dizer com relação à efetiva aprendizagem dos alunos que a frequentam. Um estudo recente publicado pela UNESCO (Gatti \& Barreto, 2009) concluiu que problemas na formação inicial e continuada dos professores, além da baixa remuneração, são aspectos que muito contribuem para a baixa qualidade do ensino oferecido.

Soares (2004) ao analisar as causas do fracasso escolar nas últimas décadas considera a perda da especificidade do processo de alfabetização como um dos fatores que podem explicar essa modalidade de fracasso. Uma das principais causas apontadas para essa perda de especificidade da alfabetização estaria relacionada à mudança conceitual a respeito do ensino e aprendizagem da língua escrita, observada a partir da década de 80 , com a hegemonia das abordagens construtivistas em educação. Tais abordagens, pelo menos da forma como têm sido apropriadas pelos professores, têm enfatizado o processo de letramento, relacionado aos usos e funções sociais da escrita, em detrimento do processo de

1 Endereço para correspondência: Av. Bandeirantes, 3900 - CEP 14040-901 - Bairro Monte Alegre - Ribeirão Preto - SP - Brasil. Email: mariaines.vitorino@ig.com.br. alfabetização, relacionado ao domínio do código escrito propriamente dito (Leite, 2010; Maluf \& Gombert, 2008; Soares, 2004).

O reconhecimento da perda da especificidade no processo de alfabetização nos leva a repensar sobre qual a melhor forma para o ensino da língua escrita, bem como sobre quais habilidades devem ser desenvolvidas na criança para que ela possa se apropriar desse objeto de conhecimento de modo mais fácil e eficiente.

A leitura e a escrita, ao contrário da fala, não são habilidades inatas do ser humano, que se desenvolvem espontaneamente, a partir da sua inserção em contextos socioculturais específicos, mas habilidades que necessitam ser aprendidas por meio de atividades de ensino sistemáticas e intencionais sobre o funcionamento do código convencional da língua escrita (Maluf, 2010; Maluf \& Gombert, 2008).

A Psicologia Cognitiva tem contribuído muito, nos últimos 40 anos, para o desenvolvimento do conhecimento sobre a aprendizagem da leitura e escrita, tanto no que se refere à elaboração de modelos para a explicação dos processos mentais envolvidos nesses comportamentos, como também no estudo das capacidades cognitivas relacionadas à sua aprendizagem. Dentre estas últimas, tem se destacado na literatura da área o conceito de habilidades metalinguísticas, as quais se referem "às capacidades de reflexão e autocontrole intencional dos tratamentos lingüísticos" (Maluf \& Gombert, 2008, p.125). 
Em um levantamento das pesquisas realizadas no Brasil, sobre a relação entre habilidades metalinguísticas e aquisição da linguagem escrita, no período de 1987 a 2005, Maluf, Zanella e Pagnez (2006) encontraram 157 trabalhos. Os resultados do levantamento efetuado indicam que o enfoque metalinguístico na explicação dos processos de aprendizagem da leitura e escrita vem ocupando espaço crescente nas investigações dos estudiosos dessa temática. É importante ressaltar também que, dos estudos analisados, mais de $50 \%$ se referiam à consciência fonológica. Essa habilidade metalinguística pode ser definida como "a consciência dos sons que compõem a fala" (Cardoso-Martins, 1991, p.42), envolvendo a capacidade para identificar e manipular intencionalmente os segmentos sonoros da língua oral. Assim, o termo consciência fonológica costuma ser usado para se referir à consciência de segmentos da fala nos níveis lexical (palavras) e sublexical (rimas, aliterações, sílabas e fonemas), utilizando-se o termo consciência fonêmica especificamente para se referir à consciência das unidades fonêmicas (Capovilla \& Capovilla, 2000a; Cardoso-Martins, 1995).

Tendo em vista que a escrita alfabética tem por princípio básico a utilização de sinais gráficos (letras ou grafemas) para representar as menores unidades da fala (fonemas), não é difícil entender por que a capacidade para analisar a fala em seus segmentos sonoros consiste em uma habilidade básica a ser desenvolvida nas práticas de alfabetização. Com efeito, a consciência fonológica tem se mostrado uma habilidade fortemente relacionada à aprendizagem da leitura e da escrita em sistemas alfabéticos, conforme demonstram inúmeras pesquisas sobre o tema (Barrera \& Maluf, 2003; Bernardino Jr., Freitas, Souza, Maranhe \& Bandini, 2006; Bradley \& Bryant, 1983; Byrne \& Fielding-Barnsley, 1989; Capovilla \& Capovilla, 2000b; Hatcher, Hulme \& Ellis, 1994; Maluf \& Barrera, 1997; Pestun, 2005; Santos, 1996).

Embora estudos correlacionais transversais não permitam a determinação de relações de causa-efeito, outros estudos de caráter longitudinal, avaliando habilidades de consciência fonológica no ingresso à primeira série (ou mesmo durante a pré-escola) e o desempenho posterior em leitura e escrita, no final do primeiro ano escolar, têm evidenciado também relações significativas entre essas competências, sugerindo que os alunos que iniciam o processo formal de alfabetização com níveis mais avançados de consciência fonológica têm melhores perspectivas de progredirem na aprendizagem da leitura e da escrita (Barrera \& Maluf, 2003; Bradley \& Bryant, 1983; Pestun, 2005) .

Por fim, vários estudos experimentais têm mostrado que grupos de alunos submetidos a procedimentos de treino em consciência fonológica, durante o processo de alfabetização, apresentam ganhos significativos em leitura e escrita quando comparados a grupos de alunos com características semelhantes e que não participaram da intervenção. Tais resultados têm sido obtidos tanto com alunos sem histórico de dificuldades escolares (Santos, 1996; Santos \& Maluf, 2004), quanto com alunos com dificuldades na alfabetização (Bernardino Jr. et al., 2006; Capovilla \& Capovilla, 2000b; Vadasy, Sanders \& Peyton, 2006; Vellutino, Scanlon, Small \& Fanuele, 2006).
Atualmente, a concepção mais aceita para explicar a relação entre consciência fonológica e aprendizagem da leitura e escrita supõe a existência de uma influência mútua entre essas habilidades. Essa hipótese "interativa" sustenta que o desenvolvimento da consciência fonológica facilita a aprendizagem da leitura e escrita, ao mesmo tempo em que a instrução formal em um sistema de escrita alfabético desenvolve ainda mais as habilidades metafonológicas, sobretudo no nível da consciência fonêmica.

Para compreender melhor essa complexa relação entre habilidades de leitura e escrita e consciência fonológica, é necessário considerar que esta última constitui uma habilidade complexa, sendo composta por diferentes níveis relacionados aos diferentes segmentos da linguagem oral passíveis de serem percebidos e analisados intencionalmente (sílabas, rimas, fonemas).

Nesse sentido, várias pesquisas têm demonstrado que as crianças pré-escolares têm maior consciência de sílabas do que de fonemas (Capovilla \& Capovilla, 2000a; Carrol, Snowling, Hulme \& Stevenson, 2003; Maluf \& Barrera, 1997). De fato, enquanto certa consciência de segmentos suprafonêmicos (sílabas e rimas, por exemplo) parece desenvolver-se, até certo ponto, de forma independente do ensino formal da língua escrita, a consciência dos segmentos fonêmicos parece depender mais fortemente de instrução explícita, sendo favorecida também pelo ensino das correspondências entre grafemas e fonemas, o que costuma ocorrer durante o processo formal de alfabetização. Tal diferença é explicada pelo fato das sílabas isoladas e outros segmentos mais amplos como as rimas, serem pronunciáveis como unidades discretas da fala, o mesmo não ocorrendo com os fonemas (com exceção dos vocálicos) os quais são de natureza mais abstrata, só se tornando manifestos como unidades discretas quando associados a outros fonemas, formando unidades maiores como as sílabas, por exemplo.

Além disso, existem variações com relação ao grau de controle consciente dos segmentos linguísticos percebidos. Assim, Gombert (2003), diferenciou entre habilidades epilinguísticas e metalinguísticas. As primeiras implicariam num conhecimento implícito e não consciente sobre a linguagem oral, manifestando-se, no caso das habilidades epifonológicas, na capacidade para perceber semelhanças sonoras entre palavras, tanto no nível silábico quanto fonêmico, bem como na identificação de rimas e aliterações. Já as habilidades metalinguísticas implicariam um controle consciente e intencional das estruturas linguísticas, resultando de aprendizagens explícitas, frequentemente de origem escolar. Nos casos das habilidades metafonológicas, as mesmas se expressariam na capacidade de analisar e manipular intencionalmente os segmentos sonoros das palavras, por exemplo, acrescentar, subtrair, inverter e contar sílabas e fonemas. De acordo com a hipótese de Gombert (2003), as habilidades epilinguísticas antecedem e facilitam a aprendizagem da leitura e escrita, sendo que esta aprendizagem, por sua vez, promove a aquisição das habilidades propriamente metalinguísticas.

De acordo com a abordagem da Psicologia Cognitiva, entender que cada palavra é constituída por uma série de fonemas, e que os fonemas são as unidades de sons representados pelas letras, é a chave para dominar o prin- 
cípio alfabético (Snow, conforme citado em Brasil, 2007). Portanto, os programas de alfabetização devem assegurar aos alunos o desenvolvimento da consciência fonêmica, a partir da instrução explícita das correspondências entre grafemas e fonemas.

Tradicionalmente os métodos de alfabetização podem ser classificados em duas grandes categorias, em função da direção dada ao ensino: sintéticos e analíticos. Os métodos sintéticos vão da parte para o todo, sendo que a parte pode ser o fonema (método fônico), a letra (método alfabético) ou a sílaba. Já os métodos analíticos vão do todo (palavras, frases ou textos) para as partes (sílabas e fonemas). Em ambos os casos enfatiza-se o trabalho com a decodificação (Brasil, 2007).

Analisando inúmeros estudos com resultados bastante satisfatórios que apontam o método fônico como o mais indicado para sanar atrasos ou dificuldades de leitura e escrita, contribuindo para prevenir e remediar o fracasso na alfabetização, alguns órgãos institucionais de países como Estados Unidos, França e Grã-Bretanha estão resgatando a importância das instruções fônicas como parte essencial de suas propostas de alfabetização (Capovilla \& Capovilla, 2000a). Outros países como Austrália, Bélgica, Canadá, Cuba, Dinamarca, Finlândia, Irlanda, Noruega e Suécia também têm reconhecido a importância do ensino explícito das correspondências entre grafemas e fonemas para facilitar a alfabetização e diminuir a incidência de dificuldades de leitura e escrita (Capovilla \& Capovilla, 2004).

Vellutino (1991), em sua revisão de pesquisas sobre a aquisição da leitura, também constatou a superioridade da abordagem fônica com relação à global, ou seja, de orientações voltadas para a decodificação ao invés de orientações voltadas para a linguagem, e que se estendiam para uma melhor compreensão do texto. Baseado nestas informações, não há evidências de que o método fônico interfira ou impeça que a criança compreenda aquilo que leu.

Por outro lado, pesquisas recentes sobre a importância das habilidades metalinguísticas em geral - e da consciência fonológica em particular - na aprendizagem da leitura e escrita, vêm dar suporte à utilização da metodologia fônica no processo de alfabetização. De acordo com Byrne e Fielding-Barnsley (1989), a aprendizagem da leitura e escrita baseia-se fundamentalmente na compreensão do princípio alfabético, que por sua vez depende de três habilidades: (a) a consciência de que é possível segmentar a língua falada em unidades distintas (fonemas); (b) a consciência de que essas mesmas unidades se repetem em diferentes palavras faladas; (c) o conhecimento das regras de correspondência entre grafemas e fonemas. É importante considerar que as duas primeiras habilidades citadas pelos autores referem-se ao constructo "consciência fonológica". O método fônico, ao focar o ensino explícito das correspondências entre grafemas e fonemas, favorece o desenvolvimento das habilidades metafonológicas de segmentação e identidade fonêmica, contribuindo assim, decisivamente para a compreensão do princípio alfabético,

É importante considerar também a hipótese de que metodologias fônicas, que objetivam o ensino explícito das relações entre letras e sons e o desenvolvimento da consciência fonológica, sejam ainda mais eficientes para a aquisição do princípio alfabético em línguas mais transparentes (regulares) como é o caso do português, do que em outras menos regulares como o francês e o inglês (Capovilla \& Capovilla, 2004).

Vale a pena enfatizar ainda que o método fônico, tal como preconizado pelas propostas mais atuais, objetiva o estabelecimento de relações entre grafemas e fonemas em meio a atividades lúdicas e reflexivas, nesse sentido,

o enfoque contemporâneo de fônica não guarda qualquer relação com meras atividades mecânicas ..., corretamente criticadas pelos partidários dos enfoques da "Whole Language”. Ao contrário, os enfoques e aplicações correntes dessa concepção pertencem ao domínio da descoberta, compreensão, reflexão e metacognição. (Brasil, 2007:72)

Tanto as avaliações internas, realizadas nas escolas, quanto as avaliações externas, realizadas em nível estadual, nacional e internacional, têm indicado o baixo rendimento dos alunos brasileiros, desde as séries iniciais do ensino fundamental ao término do ensino médio (Soares, 2004).

Por outro lado, vários estudos (Bernardino Jr. et al.; Bradley \& Bryant, 1983; Capovilla \& Capovilla, 2000b; 2006; Paula, Mota \& Keske-Soares, 2005; Santos, 1996), têm demonstrado resultados positivos na aprendizagem da leitura e escrita com a utilização de intervenções baseadas no desenvolvimento da consciência fonológica, tanto do ponto de vista preventivo quanto remediativo.

No levantamento realizado por Maluf et al. (2006), dentre as habilidades metalinguísticas pesquisadas, chama a atenção a prevalência dos estudos sobre consciência fonológica, porém as autoras referem também o número relativamente pequeno de pesquisas de intervenção, bem como daquelas realizadas com populações apresentando dificuldades de aprendizagem, embora esse panorama esteja se modificando nos últimos anos:

Nesse contexto, considerando a urgência da questão do fracasso escolar no Brasil e os avanços e lacunas ainda presentes no estudo das relações entre habilidades metafonológicas e aprendizagem da leitura e escrita, sobretudo no caso de alunos com dificuldades escolares, esta pesquisa teve como objetivo elaborar e implementar atividades de reforço escolar, baseadas no desenvolvimento da consciência fonológica e no ensino explícito da correspondência entre grafemas e fonemas, a fim de avaliar os efeitos dessa intervenção sobre a aprendizagem da leitura e escrita, em um grupo de alunos do Ensino Fundamental, apresentando graves defasagens na alfabetização.

A hipótese subjacente ao estudo foi que atividades pedagógicas que visam ao desenvolvimento da consciência fonológica e à explicitação das relações entre grafemas e fonemas podem favorecer o desenvolvimento das habilidades de leitura e escrita dos alunos, em especial daqueles que apresentam dificuldades na alfabetização.

A temática pesquisada é relevante, uma vez que a utilização da abordagem fônica na alfabetização é fonte de grandes discussões teóricas, tanto na área da Psicologia quanto da Educação. Além disso, resultados favoráveis à hipótese do estudo podem oferecer subsídios para atividades de reforço escolar que possam efetivamente contribuir para a superação das dificuldades de alfabetização. 


\section{Método}

A pesquisa foi realizada em uma Escola Pública Estadual, que atende a turmas de $1^{\mathrm{a}}$ a $8^{\mathrm{a}}$ Séries do Ensino Fundamental - Período Integral - e está situada em um bairro periférico da cidade. A preferência por esta escola deve-se ao fato de atender a uma clientela de nível socioeconômico baixo, ter atingido baixos resultados na Prova Brasil e SARESP em 2005 e funcionar em período integral, o que facilitou a realização da intervenção.

\section{Participantes}

Os participantes da pesquisa foram selecionados a partir dos resultados de uma avaliação diagnóstica de leitura e escrita, aplicada coletivamente a todos os alunos do final do ciclo I, $4^{\mathrm{a}}$ série, e de $5^{\mathrm{a}}$ a $8^{\mathrm{a}}$ séries do ciclo II, do Ensino Fundamental, da escola em questão, totalizando 150 alunos. Após a análise da avaliação diagnóstica, a amostra ficou composta por 31 alunos com importantes defasagens na alfabetização, com idade entre 09 e 21 anos (idade média de 11,9 anos), sendo 18 do sexo masculino (58\%) e 13 do sexo feminino (42\%). No início da pesquisa, 18 alunos cursavam a $4^{\mathrm{a}}$ série, dois alunos a $5^{\mathrm{a}}$ série, nove a $6^{\mathrm{a}}$ série e dois a $7^{\mathrm{a}}$ série, conforme consta na Tabela 1 .

Tabela 1. Características Gerais dos Participantes no Início do Estudo: Sexo e Série Escolar.

\begin{tabular}{lccc}
\hline Participantes & $\begin{array}{c}\text { Sexo } \\
\text { Masculino }\end{array}$ & $\begin{array}{c}\text { Sexo } \\
\text { Feminino }\end{array}$ & $\begin{array}{c}\text { Amostra } \\
\text { Total }\end{array}$ \\
\hline $4^{\text {a }}$ série & 10 & 08 & $18(58 \%)$ \\
$5^{\text {a }}$ série & 00 & 02 & $02(6,5 \%)$ \\
$6^{\text {a }}$ série & 07 & 02 & $09(29 \%)$ \\
$7^{\text {a }}$ série & 01 & 01 & $02(6,5 \%)$ \\
Total & $18(58 \%)$ & $13(42 \%)$ & $31(100 \%)$ \\
\hline
\end{tabular}

Cumpre salientar que a pesquisa foi aprovada por Comitê de Ética, sendo que os responsáveis pelos participantes assinaram o Termo de Consentimento Livre e Esclarecido - TCLE, autorizando os alunos a participarem da pesquisa.

\section{Materiais e Instrumentos}

Para a coleta de dados da pesquisa foi utilizada primeiramente a Prova de Conhecimento de Letras, composta por 23 letras $^{2}$ do alfabeto, apresentadas em formato maiúsculo, fonte Times New Roman, tamanho 72, em ordem aleatória. A tarefa da criança era nomear as letras apontadas pela pesquisadora, sendo atribuído um ponto para cada resposta certa, com pontuação máxima possível de 23 pontos.

Em seguida foi realizada a Prova de Consciência Fonológica (PCF) (Capovilla \& Capovilla, 2000a) para avaliar

2 Na época da realização da coleta de dados ainda não estavam em vigor no Brasil as mudanças ortográficas que incorporaram ao alfabeto as letras $\mathrm{K}, \mathrm{W}$, e Y. as habilidades de identificação e manipulação dos sons da fala. A prova é composta por dez subtestes - segmentação silábica, síntese silábica, aliteração, rimas, manipulação silábica, transposição silábica, síntese fonêmica, manipulação fonêmica, transposição fonêmica e segmentação fonêmica -, sendo cada um deles composto por dois itens de treino e quatro itens de teste. O resultado das crianças na PCF é apresentado como escore ou frequência de acertos, sendo a pontuação máxima possível de 40 pontos. A PCF apresenta bons índices de confiabilidade, tanto para o escore geral $(\mathrm{r}$ variando de 0,90 a 0,80 com $p=0,0001$ ), quanto para os diferentes subtestes ( $r$ variando de 0,55 a 0,83 com $p=0,0001$ ), exceto para Síntese e Segmentação Silábicas. Quanto à validade da prova, os escores específicos em cada subteste são válidos para discriminar entre diferentes níveis escolares e idades, e estão relacionados a habilidades de leitura e escrita, com exceção dos subtestes de Síntese e Segmentação Silábicas e Rima, que são os mais fáceis da PCF (Capovilla \& Capovilla, 2000b).

Na sequência foram realizadas as Provas de Leitura e Escrita do TDE - Teste de Desempenho Escolar (Stein, 1994). O TDE é um teste que busca oferecer de forma objetiva uma avaliação das capacidades de leitura, escrita e aritmética. $\mathrm{O}$ teste foi concebido para ser aplicado em escolares de $1^{\mathrm{a}}$ a $6^{\mathrm{a}}$ séries, podendo ser estendido para $7^{\mathrm{a}}$ e $8^{\mathrm{a}}$ séries do Ensino Fundamental, como foi o caso da pesquisa realizada, e foi fundamentado em critérios elaborados a partir da realidade escolar brasileira. Os subtestes de Leitura e Escrita (ditado) são compostos por 70 e 34 palavras, respectivamente, apresentadas em ordem crescente de dificuldade, totalizando uma pontuação máxima de 70 pontos para a leitura e 34 pontos para a escrita. $\mathrm{O}$ teste apresenta elevado índice de consistência interna (confiabilidade) e bom índice de validade para discriminar os alunos em função do desempenho, com normas de acordo com a idade e a série (Stein, 1994).

O material utilizado para a intervenção foi apoiado nas obras de Capovilla e Capovilla (2004), Araújo e Araújo (2002), e Jardini (2003). Foram utilizados também os seguintes materiais: alfabeto móvel; CD-ROM - Alfabetização Fônica Computadorizada (Capovilla, Capovilla \& Macedo, 2005); jogo de memória das vogais; jogo de memória do alfabeto; jogo dominó (desenhos/palavras); software editora Ática - assessoria pedagógica do livro "Construindo a Escrita” (Carvalho, Panachão, Kutnikas \& Salmaso, 2005).

\section{Procedimentos}

A pesquisa foi composta pelas seguintes fases: avaliação diagnóstica coletiva para seleção dos participantes; pré-teste, composto por uma avaliação individual das habilidades de conhecimento de letras, consciência fonológica, leitura e escrita; intervenção de reforço escolar baseada numa metodologia fônica; e pós-teste, com a reavaliação das mesmas habilidades do pré-teste, a fim de analisar os efeitos da intervenção sobre a aprendizagem da leitura e escrita.

Inicialmente, os participantes foram divididos em dois grupos, de acordo com o grau de dificuldade apresentado no pré-teste, sendo: um grupo mais avançado, que já dominava de forma básica o princípio alfabético das correspondências 
letra-som, composto por 11 crianças (Grupo A), e um grupo no início da alfabetização, composto por 20 crianças (Grupo B). Cada grupo participou de duas sessões de intervenção por semana, com duração de duas horas cada, ministradas pela pesquisadora, fora do período diário de aulas, durante um período de dez meses.

O carro chefe das atividades de intervenção foi o livro do aluno "Alfabetização Fônica" (Capovilla \& Capovilla, 2004). Com relação à sequência didática, os autores não seguem a ordem do abecedário, mas trabalham de acordo com o grau de dificuldade crescente das letras. Primeiramente, são apresentadas as vogais (A, E, I, O, U), devido à semelhança entre o nome da letra e o seu som. Em seguida, as consoantes prolongáveis, ou seja, aquelas cujos sons podem ser facilmente pronunciados de forma isolada, como: F, J, M, N, V e Z. Depois, as consoantes de fácil pronúncia de forma isolada, mas que possuem mais de um som, como: L, S, R e X. Nestas letras, são apresentados apenas os sons regulares e mais frequentes. Os sons irregulares são introduzidos posteriormente, em outras atividades. Finalmente são introduzidas as consoantes cujos sons são mais difíceis de serem pronunciados de forma isolada: B, P, D, T, C, e G. Da mesma forma, para estas duas últimas letras são apresentados primeiramente apenas os sons regulares. A seguir, apresenta-se a letra H, que é uma exceção, já que não possui nenhum som. As letras K, W e Y são apresentadas na sequência. Após a apresentação dos sons regulares de todas as letras, inicia-se a apresentação das correspondências grafo-fonêmicas irregulares. Há atividades específicas para a introdução dos dígrafos $\mathrm{CH}, \mathrm{NH}, \mathrm{LH}, \mathrm{RR}, \mathrm{SS}, \mathrm{GU}$ e QU, para a introdução dos sons irregulares das letras C, G, R, S, L, M e X, e para a introdução da cedilha e dos encontros consonantais.

Durante a intervenção procurou-se também utilizar estratégias lúdicas, como jogos (Jardini, 2003), cruzadinhas e caça-palavras (Araújo \& Araújo, 2002), de modo a favorecer a motivação e a desenvolver a autoestima dos alunos. Foram realizadas também atividades no computador. Os alunos do Grupo B trabalharam com o CD-ROM - Alfabetização Fônica Computadorizada (Capovilla \& Capovilla, 2005) e os do Grupo A, com o software da editora Ática (Carvalho et al., 2005), com os quais desenvolviam jogos pedagógicos relacionados à ortografia, à ampliação do vocabulário, à formação de novas palavras a partir de trocas de letras/fonemas de uma palavra-chave, dentre outras (para maiores detalhes sobre os procedimentos de intervenção, vide Justino, 2010).

Após o término da intervenção foi realizado o pós-teste, a partir da utilização dos mesmos instrumentos e seguindo a mesma forma de aplicação do pré-teste (Prova de Conhecimento de Letras, Consciência Fonológica, Leitura e Escrita).

\section{Resultados}

Uma análise preliminar dos resultados obtidos 3 mostrou que, das quatro variáveis pesquisadas, a saber: conhecimento de letras, leitura, escrita e consciência fonológica, apenas a última apresentava distribuição normal da diferença entre pré e pós-teste, motivo pelo qual se optou por utilizar o teste não paramétrico de Wilcoxon para amostras pareadas, a fim de analisar os possíveis efeitos da intervenção (comparações pré-teste $\mathrm{x}$ pós-teste).

A Tabela 2 apresenta os resultados gerais da pesquisa realizada, com a pontuação média dos participantes nas provas aplicadas e os resultados da análise estatística das diferenças obtidas entre o pré e o pós-teste, indicando que, para todas as habilidades avaliadas, a diferença foi significativa, tanto para a amostra total quanto para os grupos com maior dificuldade (Grupo B) e menor dificuldade (Grupo A).

3 Teste Shapiro-Wilks, adotando como nível de significância $\mathrm{p} \leq 0,05$.

Tabela 2. Escores Médios dos Participantes nas Provas Aplicadas e Resultados do Teste de Wilcoxon (Z) para a Comparação Pré-Teste x Pós-Teste.

\begin{tabular}{|c|c|c|c|c|c|c|c|c|}
\hline \multirow[t]{2}{*}{ Provas } & \multicolumn{2}{|c|}{ Conhecimento de Letras } & \multicolumn{2}{|c|}{ Consciência Fonológica } & \multicolumn{2}{|c|}{ Prova de Leitura } & \multicolumn{2}{|c|}{ Prova de Escrita } \\
\hline & Pré-teste & Pós-teste & Pré-teste & Pós-teste & Pré-teste & Pós-teste & Pré-teste & Pós-teste \\
\hline \multirow{2}{*}{$\begin{array}{l}\text { Amostra Total } \\
(\mathrm{N}=31)\end{array}$} & 18,31 & 22,03 & 14,42 & 26,81 & 17,52 & 44,1 & 3,26 & 11,97 \\
\hline & \multicolumn{2}{|c|}{$\mathrm{Z}=4,23(\mathrm{p}<0,001)$} & \multicolumn{2}{|c|}{$\mathrm{Z}=4,71(\mathrm{p}<0,001)$} & \multicolumn{2}{|c|}{$\mathrm{Z}=4,75(\mathrm{p}<0,001)$} & \multicolumn{2}{|l|}{$\begin{array}{l}Z=4,46 \\
(p<0,001)\end{array}$} \\
\hline \multirow{2}{*}{$\begin{array}{l}\text { Grupo A } \\
(\mathrm{N}=11)\end{array}$} & 22,45 & 23,00 & 19.91 & 33,00 & 42,18 & 64,18 & 8,00 & 18,09 \\
\hline & \multicolumn{2}{|c|}{$\mathrm{Z}=2,45(\mathrm{p}=0,01)$} & \multicolumn{2}{|c|}{$\mathrm{Z}=2,94(\mathrm{p}=0,003)$} & \multicolumn{2}{|l|}{$\begin{array}{l}Z=2,93 \\
(p=0,003)\end{array}$} & \multicolumn{2}{|c|}{$\begin{array}{l}Z=2,94 \\
(p=0,003)\end{array}$} \\
\hline \multirow{2}{*}{$\begin{array}{l}\text { Grupo B } \\
(\mathrm{N}=20)\end{array}$} & 16,02 & 21,5 & 11,4 & 23,40 & 3,95 & 33,05 & 0,65 & 8,60 \\
\hline & \multicolumn{2}{|l|}{$\begin{array}{l}Z=3,63 \\
(p<0,001)\end{array}$} & \multicolumn{2}{|l|}{$\begin{array}{l}Z=3,73 \\
(p<0,001)\end{array}$} & \multicolumn{2}{|l|}{$\begin{array}{l}Z=3,78 \\
(p=0,001)\end{array}$} & \multicolumn{2}{|l|}{$\begin{array}{l}Z=3,41 \\
(p=0,001)\end{array}$} \\
\hline
\end{tabular}


Cumpre esclarecer que o Grupo A foi composto por 11 alunos que, já no pré-teste, se encontravam no estágio alfabético segundo a classificação de Ferreiro (1990) e que, além disso, alcançaram pontuação superior à média do grupo na prova de escrita, que foi de três pontos. Porém, esses alunos apresentavam ainda muitas dificuldades tanto na leitura como na escrita, pois a maior parte deles dominava apenas as relações mais regulares entre grafemas e fonemas, cometendo ainda muitos erros de ortografia e também na leitura. Por outro lado, foram designados para o Grupo B, aqueles alunos que obtiveram, por ocasião do pré-teste, pontuação na prova de escrita inferior à pontuação média obtida pela amostra total. Todos eles apresentavam também pontuação em leitura abaixo da média do grupo.

Os resultados da Prova de Conhecimento de Letras indicaram uma grande heterogeneidade dos participantes no que se refere a essa competência, sendo que, enquanto uma parte dos alunos já apresentava um bom domínio do nome das letras do alfabeto, outro subgrupo apresentava ainda um conhecimento bastante pequeno desse repertório, apesar de já estarem no ensino fundamental há pelo menos quatro anos. Nessa prova, foi obtida diferença significativa entre o pré e o pós-teste, sugerindo a efetividade da intervenção realizada para o domínio desse conhecimento, uma vez que, enquanto no pré-teste apenas oito participantes $(26 \%)$ demonstraram conhecer todo o alfabeto, esse número subiu para 25 (81\%) no pós-teste.

É importante salientar que, no início da pesquisa, os alunos do Grupo A já conheciam, em média, 22 letras do alfabeto, enquanto no Grupo B esse valor caía para apenas 16 letras. Tal resultado sugere que o conhecimento do nome das letras parece se constituir numa habilidade fortemente associada ao domínio do código alfabético.

$\mathrm{Na}$ Prova de Escrita também foi obtida diferença significativa entre o pré e o pós-teste, sugerindo que a intervenção realizada contribuiu para a aprendizagem da escrita dos participantes. No pré-teste, dez alunos encontravam-se no estágio pré-silábico de escrita, cinco alunos apresentavam produções escritas próprias do estágio silábico e/ou silábico-alfabético e 16 encontravam-se no estágio alfabético, segundo a classificação de Ferreiro (1990), porém a maioria destes apresentando inúmeras dificuldades ortográficas, até mesmo nas sílabas simples (CV). Após a intervenção, cinco alunos permaneceram no estágio pré-silábico, enquanto os outros 26 foram classificados no estágio alfabético de escrita. Dos alunos que avançaram, todos demonstraram compreensão das relações mais regulares entre grafemas e fonemas, necessitando apenas aprimorar em maior ou menor grau o domínio das irregularidades do sistema ortográfico de escrita.

No caso da Prova de Leitura, a diferença entre o pré e pós-teste também foi significativa, sugerindo que a intervenção realizada foi bastante efetiva no sentido de desenvolver essa habilidade. O resultado obtido na prova de leitura foi bem animador, uma vez que, na realização do pré-teste, nove alunos não haviam conseguido ler nenhuma palavra, 13 alunos tiveram um desempenho abaixo da média do grupo (inferior a 17 pontos) e apenas nove alunos pontuaram acima da média. Após a intervenção, 20 alunos conseguiram um bom desempenho, ficando acima do resultado médio do grupo nessa fase (que subiu para 44 pontos).

No caso das habilidades de consciência fonológica, observou-se que as diferenças obtidas entre o pré e o pós-teste também foram significativas, sugerindo a eficácia da intervenção realizada para o desenvolvimento dessa habilidade metalinguística. A Figura 1 apresenta a média de acertos obtida pelos sujeitos da pesquisa em cada subteste da prova de consciência fonológica, no pré e pós-teste, indicando a precedência das habilidades metafonológicas de nível silábico quando comparadas às habilidades de nível fonêmico.

Os resultados da Prova de Consciência Fonológica demonstram que, de modo geral, os 31 participantes apresentaram pouco domínio metafonológico no pré-teste, porém, nas habilidades que se referiam à síntese e segmentação silábica, apesar de possuírem uma grave defasagem na alfabetização, tiveram um bom desempenho. $\mathrm{O}$ fato de o grupo ter tido melhor desempenho nos subtestes de síntese e segmentação silábica, tanto no pré como no pós-teste, quando comparado aos resultados obtido nos subtestes de síntese, segmentação, manipulação e transposição fonêmica, nos quais demonstraram muitas dificuldades, indica a maior complexidade da análise fonológica no nível fonêmico, a qual é concebida como dependente, em grande parte, do domínio do código alfabético. Cabe ressaltar que, no pré-teste, muitos alunos zeraram nos subtestes de segmentação e transposição fonêmica. Já no pós-teste, houve uma evolução importante do grupo nesses subtestes e mesmo nos

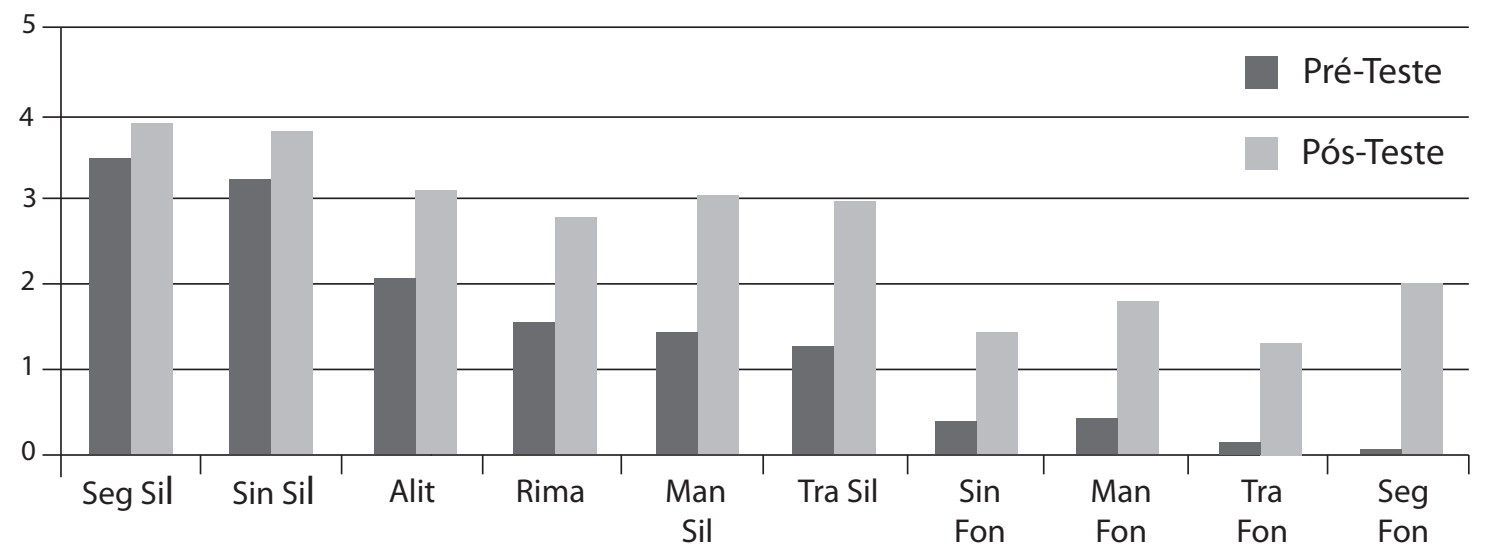

Figura 1. Pontuação média dos participantes (amostra total) nos subtestes da Prova de Consciência Fonológica: Comparação pré-teste x pós-teste 
subtestes de manipulação e transposição silábica, subtestes esses que envolvem controle consciente e explícito das unidades sonoras da língua oral.

\section{Discussão}

Os resultados obtidos sugerem relações importantes entre conhecimento de letras e aprendizagem da leitura e da escrita. Com efeito, resultados de alguns estudos (Cardoso-Martins \& Batista, 2005; Cardoso-Martins, Correa \& Marchetti, 2008; Kim, Petscher, Foorman \& Zhou, 2010) mostram que o conhecimento do alfabeto tem uma correlação estreita com o progresso inicial na alfabetização. De acordo com os resultados de Kim et al. (2010), as habilidades metafonológicas têm maior efeito preditivo sobre o conhecimento das relações letra-som quando os nomes das letras são conhecidos, provavelmente pelo fato de que esse conhecimento oferece pistas cruciais sobre o som que cada letra representa, auxiliando a criança no domínio do princípio alfabético.

Quanto aos resultados favoráveis da intervenção no que se refere às habilidades de leitura e escrita, o presente estudo vem apoiar a eficácia da utilização de abordagens fônicas de alfabetização na superação das dificuldades de aprendizagem da leitura e da escrita. Segundo Carnio e Santos (2005), o processo de alfabetização é facilitado quando as crianças, ao ingressarem na escola, já dispõem de um considerável background de experiências informais com a linguagem escrita, nas quais conseguem diferenciar os usos sociais da mesma, sua importância e sua relação com a oralidade. Porém, esse não é o perfil das crianças que tem chegado às escolas públicas, as quais geralmente vivenciam experiências mais limitadas nesse sentido. Entretanto, é função da escola propiciar essas experiências e estimular a reflexão intencional da criança a respeito das relações entre a linguagem oral e a escrita.

Os dados obtidos indicam também a maior facilidade da leitura quando comparada à escrita, confirmando os resultados da pesquisa de Paolucci e Ávila (2009), realizada com alunos da $4^{\mathrm{a}}$ série. Essa discrepância possivelmente é devida ao maior grau de regularidade na leitura (correspondências letra/som) do que na escrita (correspondências som/letra), pelo menos no que se refere à língua portuguesa.

Outro fator que pode ter contribuído para um melhor resultado dos participantes na prova de leitura está relacionado à própria estrutura da prova aplicada, que permitia a autocorreção, sendo que muitas vezes, quando o aluno percebia que a decodificação realizada não correspondia a uma palavra conhecida, fazia uso dessa informação para, a partir das pistas fonológicas obtidas com a tentativa de decodificação, deduzir a leitura correta da palavra em questão.

Com relação à melhora dos níveis de consciência fonológica com a intervenção, de modo geral os resultados obtidos vêm ao encontro de outros presentes na literatura (Bernardino Jr. et al., 2006; Paula et al., 2005), que demonstram progressos significativos em leitura, escrita e habilidades metafonológicas em alunos com dificuldades de aprendizagem submetidos ao treinamento em consciência fonológica e ao ensino explícito das correspondências entre grafemas e fonemas.
Vários estudos têm sugerido (Barrera \& Maluf, 2003; Capovilla \& Capovilla, 2000; Maluf et al., 2006; Pestun, 2005) que a consciência fonológica desempenha um importante papel facilitador no processo de aprendizagem tanto da leitura quanto da escrita. A presença dessa habilidade metalinguística no início da alfabetização seria preditora de melhores resultados na aquisição inicial da linguagem escrita.

É possível atribuir grande parte dos bons resultados obtidos nos pós-testes de leitura e escrita a esse progresso em termos de consciência fonológica, pois essa habilidade metalinguística tem se mostrado diretamente relacionada aos progressos em alfabetização sendo considerada, se não um fator suficiente, pelo menos um fator necessário para o domínio do código alfabético.

Conforme apontam Barrera e Maluf (2003), a hipótese mais aceita atualmente para explicar as relações entre consciência fonológica e alfabetização supõe a existência de uma influência mútua entre essas habilidades. Entretanto, há fortes evidências também de que alguns níveis de conhecimento metafonológico antecedem e facilitam a aprendizagem e o domínio do código alfabético, sobretudo conhecimentos implícitos a respeito da estrutura sonora da língua, especialmente aqueles relacionados a segmentos silábicos ou suprassilábicos, sendo que os progressos em alfabetização levariam ao desenvolvimento de competências metafonológicas de níveis mais complexos, como é o caso da consciência explícita dos fonemas (Barrera \& Maluf, 2003; Capovilla \& Capovilla, 2000a; Cardoso-Martins, 1995).

É possível supor que a experiência escolar anterior dos alunos tenha contribuído para o desenvolvimento de habilidades básicas de consciência fonológica (em nível silábico e implícito), e que a realização das atividades desenvolvidas durante a intervenção tenha contribuído para um maior desenvolvimento e refinamento dessas habilidades a nível fonêmico e explícito. Isso nos leva a pensar que estas habilidades não foram adequadamente exploradas e desenvolvidas pela escola, no sentido de possibilitarem a efetiva alfabetização desses alunos.

É preciso levar em conta ainda, que a consciência fonológica é fator necessário, porém não suficiente para a aprendizagem da leitura e escrita, a qual depende também do desenvolvimento de outras habilidades metalinguísticas, como a consciência de aspectos morfológicos e sintáticos da língua, os quais têm se mostrado relacionados à competência ortográfica, por exemplo (Meireles \& Correa, 2005).

Os resultados obtidos nesta pesquisa vêm fortalecer a hipótese da eficácia da abordagem fônica como estratégia pedagógica de reforço escolar para trabalhar com alunos do Ensino Fundamental com importantes defasagens na alfabetização. A análise estatística realizada indica que a amostra de alunos pesquisada obteve progressos significativos entre o pré e pós-teste em todas as habilidades avaliadas, a saber: conhecimento de letras, consciência fonológica, leitura e escrita.

Os resultados obtidos vão na direção daqueles apresentados no estudo realizado por Vellutino et al. (2006), nos levando a refletir sobre a importância das condições de aprendizagem, tanto no que diz respeito aos fatores instrucionais (metodologia, estratégia pedagógica e formação de professores), quanto ambientais (estímulo e condições de 
ensino), que poderiam estar contribuindo para que muitos alunos não consigam desenvolver as habilidades de leitura e escrita.

Nesse sentido é importante realizar também uma reflexão sobre as políticas públicas atuais para a alfabetização que, ao privilegiarem as práticas pedagógicas voltadas para o letramento (conhecimentos dos usos e funções sociais da língua escrita), muitas vezes acabam por negligenciar a importância do trabalho com a reflexão e a sistematização do código alfabético (Maluf \& Gombert, 2008).

Dispomos atualmente de considerável evidência empírica de que a incorporação da abordagem fônica às metodologias de alfabetização constitui um recurso bastante eficaz para promover a aprendizagem da leitura e escrita, uma vez que, ao privilegiar o ensino sistemático e explícito das letras do alfabeto e dos fonemas a elas associados, favorece o desenvolvimento da consciência fonológica, habilidade metalinguística básica para o domínio do princípio alfabético, princípio esse que constitui a chave-mestra para o funcionamento do código, que reside no domínio das correspondências grafo-fonêmicas.

A despeito da metodologia utilizada na intervenção e das condições de trabalho adequadas, alguns alunos do Grupo B (cerca de $20 \%$ da amostra) praticamente não obtiveram progressos na alfabetização. A metade destes teve frequência muito reduzida nas atividades de intervenção, o que poderia explicar, a princípio, as dificuldades encontradas, embora seja difícil afirmar com certeza, uma vez que as faltas também podem ser uma resposta às dificuldades percebidas. Dois destes alunos apresentavam problemas biológicos comprovados, sendo que, nos demais casos, a hipótese de um comprometimento neurológico responsável por essas dificuldades (dislexia) também não está descartada. Caso esta hipótese se confirme, seria necessário pensar num atendimento mais individualizado (ou até mesmo especializado) para minimizar as dificuldades desses alunos.

Finalmente, é importante considerar que as diferenças entre o pré e o pós-teste obtidas no presente estudo não são conclusivas para se afirmar a eficácia da intervenção realizada, uma vez que uma limitação do estudo foi o delineamento da pesquisa não utilizar grupo controle, o que teria permitido comparar, de forma mais fidedigna, os progressos decorrentes da intervenção com possíveis progressos que poderiam ter ocorrido devido a efeitos de maturação e/ou à simples exposição escolar ao ensino regular, durante o tempo de realização da pesquisa. Questões de ordem ética e também relativas ao número de participantes da pesquisa, de modo a favorecer análises estatísticas mais robustas, nos levaram deliberadamente a não utilizar um grupo controle no delineamento da pesquisa. Entretanto, dado o grau de defasagem dos participantes em termos de alfabetização no início do estudo, é difícil supor que apenas a frequência ao ensino regular pudesse ter sido responsável pela melhora observada, uma vez que esses alunos já vinham sendo expostos a condições educacionais regulares por vários anos, obtendo pouco ou nulo progresso em sua alfabetização.

As evidências dos resultados obtidos nos levam a acreditar e a apostar na capacidade de aprendizagem desses alunos. A pergunta é: seria a escola a responsável pelo fracasso dos mesmos? Tudo leva a crer que ocorreria um bom aprovei- tamento e assimilação da aprendizagem se houvesse um trabalho pedagógico direcionado para as necessidades dos alunos com um maior nível de dificuldade, principalmente nas aulas de reforço escolar. Um ambiente favorável, uma metodologia adequada e um profissional interessado e capacitado para implementá-la contribuiria, sem dúvida, para a aprendizagem e o crescimento pessoal desses alunos.

\section{Referências}

Araújo, V., \& Araújo, R. (2002). Alfabetização divertida. Belo Horizonte: FAPI.

Barrera, S. D., \& Maluf, M. R. (2003). Consciência metalinguística e alfabetização: um estudo com crianças da $1^{\mathrm{a}}$ série do ensino fundamental. Psicologia: Reflexão e Crítica, 16, 491-502.

Bernardino Júnior, J. A., Freitas, F. R., Souza, D. G., Maranhe, E. A., \& Bandini, H. H. M. (2006). Aquisição de leitura e escrita como resultado do ensino de habilidades de consciência fonológica. Revista Brasileira de Educação Especial, 12, 423-450.

Bradley, L., \& Bryant, P. E. (1983). Categorizing sounds and learning to read: A causal connection. Nature, 301, 419-421.

Byrne, B., \& Fielding-Barnsley, R. (1989). Phonemic awareness and letter knowledge in the child's acquisition of the alphabetic principle. Journal of Educational Psychology, 81, 313-321.

Brasil (2007). Alfabetização infantil: os novos caminhos. Relatório apresentado à Comissão de Educação e Cultura da Câmara dos Deputados. Brasília, DF. Disponível em http://bd.camara.gov. br/bd/bitstream/handle/bdcamara/1924/grupo_alfabetizacao_ infantil_educacao_cultura.pdf?sequence $=1$

Capovilla, A. G. S., \& Capovilla, F. C. (2000a). Problemas de leitura e escrita: como identificar, prevenir e remediar numa abordagem fônica. São Paulo: Memnon.

Capovilla, A. G. S., \& Capovilla, F. C. (2000b). Efeitos do treino de consciência fonológica em crianças com baixo nível sócioeconômico. Psicologia: Reflexão e Crítica. 13, 07-24.

Capovilla, A. G. S., \& Capovilla, F. C. (2004). Alfabetização: método fônico ( $3^{\mathrm{a}}$ ed.). São Paulo: Memnon.

Capovilla, A. G. S., Capovilla, F. C., \& Macedo, E. C. (2005). Alfabetização fônica computadorizada: fundamentação teórica e guia para o usuário. São Paulo: Memnon.

Cardoso-Martins, C. (1991). A consciência fonológica e a aprendizagem inicial da leitura e da escrita. Cadernos de Pesquisa, 76, 41-49.

Cardoso-Martins, C. (1995). Sensitivity to rhymes, syllables and phonemes in literacy acquisition in Portuguese. Reading Research Quarterly, 30, 808-827.

Cardoso-Martins, C., \& Batista, A. C. E. (2005). O conhecimento do nome das letras e o desenvolvimento da escrita: evidência de crianças falantes do português. Psicologia: Reflexão $e$ Crítica, 18, 330-336.

Cardoso-Martins, C., Corrêa, M. F., \& Marcheti, P. M. T. (2008). O conhecimento do nome das letras e o desenvolvimento inicial da escrita: o caso do português do Brasil. In M. R. Maluf \& S. R. K. Guimarães (Eds.), Desenvolvimento da Linguagem Oral e Escrita (pp. 137-153). Curitiba: Editora UFPR.

Carnio, M. S., \& Santos, D. (2005). Evolução da consciência fonológica em alunos de ensino fundamental. Pró-Fono, $17,195-200$. 
Carrol, J. M., Snowling, M. J., Hulme, C., \& Stevenson, J. (2003). The development of phonological awareness in preschool children. Developmental Psychology, 39, 913-923.

Carvalho, C. S. C., Panachão, D., Kutnikas, S. B., \& Salmaso, S. M. A. (2005). Construindo a escrita. São Paulo: Ática.

Ferreiro, E. (1990). A Escrita... antes das letras. In H. Sinclair (Ed.), A produção de notações na criança (pp. 19-70). São Paulo: Cortez: Autores Associados.

Gatti, B. A., \& Barreto, E. de S. (2009). Professores do Brasil: impasses e desafios. Brasília: UNESCO.

Gombert, J. E. (2003). Atividades metalinguísticas e aprendizagem da leitura. In M. R. Maluf (Ed.), Metalinguagem e aquisição da escrita (pp. 19-63). São Paulo: Casa do Psicólogo.

Hatcher, P. J., Hulme, C., \& Ellis, A. W. (1994). Ameliorating early reading failure by integrating the teaching of reading and phonological skills: the phonological linkage hypothesis. Child Development, 65, 41-57.

Jardini, R. S. R. (2003). "Método das boquinhas"- Alfabetização e reabilitação dos distúrbios da leitura e escrita. São Paulo: Casa do Psicólogo.

Justino, M. I. S. V. (2010). Efeitos do reforço escolar numa abordagem fônica em alunos do ensino fundamental com graves defasagens na alfabetização. Dissertação de Mestrado, Universidade de São Paulo, Ribeirão Preto.

Kim, Y. S., Petscher, Y., Foorman, B. R., \& Zhou, C. (2010). The contributions of phonological awareness and lettername knowledge to letter-sound acquisition: A crossclassified multilevel model approach. Journal of Educational Psychology, 102, 313-326.

Leite, S.A. S. (2010). Alfabetização: em defesa da sistematização do trabalho pedagógico. In V. A. Arantes (Ed.), Alfabetização e letramento (pp.15-74). São Paulo: Summus.

Maluf, M. R. (2010). Do conhecimento implícito à consciência metalingüística indispensável na alfabetização. In S. R. K. Guimarães \& M. R. Maluf (Eds.), Aprendizagem da linguagem escrita: contribuições da pesquisa (pp.17-32). São Paulo: Vetor.

Maluf, M. R., \& Barrera, S. D. (1997). Consciência fonológica e linguagem escrita em pré-escolares. Psicologia: Reflexão $e$ Crítica, 10, 125-145.

Maluf, M. R., \& Gombert, J. E. (2008) Habilidades implícitas e controle cognitivo na aprendizagem da linguagem escrita. In M. R. Maluf \& S.R. K. Guimarães (Eds.), Desenvolvimento da linguagem oral e escrita (pp. 123-135). Curitiba: Editora UFPR.

Maluf, M. R., Zanella, M. S., \& Pagnez, K. S. M. M. (2006). Habilidades metalinguísticas e linguagem escrita nas pesquisas brasileiras. Boletim de Psicologia, 56(124), 67-92.

Meireles E. S., \& Correa J. (2005). Regras contextuais e morfossintáticas na aquisição da ortografia da língua portuguesa por criança. Psicologia: Teoria e Pesquisa, 21, 77-84.
Paolucci, J. F., \& Ávila, C. R. B. (2009). Competência ortográfica e metafonológica: influências e correlações na leitura e escrita de escolares da $4^{\mathrm{a}}$ série. Revista da Sociedade Brasileira de Fonoaudiologia, 14, 48-55.

Paula, G. R., Mota, H., \& Keske-Soares, M. (2005). A terapia em consciência fonológica no processo de alfabetização. Pró-fono, 17, 175-184.

Pestun, M. S. V. (2005). Consciência fonológica no início da escolarização e o desempenho ulterior em leitura e escrita: estudo correlacional. Estudos de Psicologia, 10, 407-412.

Santos, A. A. A. (1996). A influência da consciência fonológica na aquisição da leitura e da escrita. In F. F. Sisto et al. (Eds.), Atuação psicopedagógica e aprendizagem escolar (pp. 213247). Petrópolis: Vozes.

Santos, M. J., \& Maluf, M. R. (2004). Consciência fonológica e linguagem escrita: efeitos de um programa de intervenção. In M. R. Maluf (Ed.), Psicologia Educacional: questões contemporâneas (pp. 91-103). São Paulo: Casa do Psicólogo.

Soares, M. (2004). Letramento e alfabetização: as muitas facetas [versão eletrônica]. Revista Brasileira de Educação, 25, 5-17.

Stein, L. M. (1994). Teste de Desempenho Escolar (TDE): Manual para aplicação e interpretação. São Paulo: Casa do Psicólogo.

Vadasy, P. F., Sanders, E. A., \& Peyton, J. A. (2006) Code-oriented instruction for kindergarten students at risk for reading difficulties: a randomized field trial with paraeducator implementers. Journal of Educational Psychology, 98, $508-528$.

Vellutino, F. (1991). Introduction to three studies on reading acquisition: Convergent findings on theoretical foundations of code-oriented versus whole-language approaches to reading instruction. Journal of Educational Psychology, 83, 437-443.

Vellutino, F., Scanlon, D. N., Small, S., \& Fanuele, D. P. (2006). Response to intervention as a vehicle for distinguishing between children with and without reading disabilities: Evidence for the role of kindergarten and first-grade interventions. Journal of Learning Disabilities, 39, 157-169. 